\title{
Charpy Impact Value of Sandwich Structural (CFRP/ABS/CFRP) Composites Constructed with Carbon Fiber Reinforced Epoxy Polymer (CFRP) and Acrylonitrile Butadiene Styrene (ABS) Sheets Separately Irradiated by Electron Beam Prior to Lamination
}

\author{
Naoya Tsuchikura*, Michael C. Faudree and Yoshitake Nishi \\ Department of Metallurgical Engineering, Graduate School of Engineering, Tokai University, Hiratsuka 259-1292, Japan
}

\begin{abstract}
Experimental results showed homogeneous $100 \mathrm{keV}$-class low voltage electron beam irradiation (HLEBI) prior to lamination assembly (our new method) often improved the Charpy impact values $\left(a_{\mathrm{uc}}\right)$ of the sandwich structural CFRP/ABS/CFRP (carbon fiber reinforced epoxy polymer) and (acrylonitrile butadiene styrene) with low volume fraction of carbon fibers for cost reduction and safety. The $a_{\mathrm{uc}}$ values at each $P_{\mathrm{f}}$ of CFRP/ABS/CFRP laminated by both high-strength and light structural CFRP plies and ABS core separately irradiated from 0.04 to $0.30 \mathrm{MGy}-\mathrm{HLEBI}$ before lamination were mostly higher than that without HLEBI. Although carefulness for aircraft parts would be necessary since higher doses of 0.30 and $0.43 \mathrm{MGy}$ HLEBI applied to the CFRP sheets and ABS core before lamination assembly reduced the lowest impact value at $P_{\mathrm{f}}=0\left(a_{\mathrm{s}}\right)$ calculated by 3-parameter Weibull equation, the low dose of 0.04 MGy-HLEBI before lamination assembly apparently boosted the $a_{\mathrm{s}}$ almost 3 times, $\sim 200 \%$, over the untreated samples from 15 to $44 \mathrm{~kJ} \mathrm{~m}{ }^{-2}$. Moreover, applying the low dose of $0.04 \mathrm{MGy}-\mathrm{HLEBI}$ before instead of after lamination apparently improved the $a_{\mathrm{s}} 76 \%$ from 25 to $44 \mathrm{~kJ} \mathrm{~m}^{-2}$. Furthermore, applying the medium doses of $0.13 \mathrm{MGy}$ or $0.22 \mathrm{MGy}$ HLEBI before rather than after lamination appeared to improve the $a_{\mathrm{s}}$ remarkably from 0 to 40 , and 0 to $42 \mathrm{~kJ} \mathrm{~m}^{-2}$, respectively. The new method of applying HLEBI prior to lamination allows for more efficient beam contact to the inner core and its surface permitting deeper areas in thick laminated composites such as CFRP/ABS/CFRP to be treated generating dangling bonds, hence strengthening the bulk materials and the CFRP-ABS interface of the thick laminated CFRP/ABS/CFRP constructed with thin or thick surface sheet and thick core can be expected. [doi:10.2320/matertrans.MBW201209]
\end{abstract}

(Received October 15, 2012; Accepted December 19, 2012; Published February 25, 2013)

Keywords: sandwich structure, carbon fiber reinforced epoxy polymer (CFRP), epoxy, acrylonitrile butadiene styrene (ABS), Charpy impact test, electron beam irradiation

\section{Introduction}

The strengthening of light structural materials has been always required to develop high-speed transport vehicles with safety enhancement and low energy consumption. Carbon fiber reinforced epoxy polymers (CFRP) are typical light structural materials with high strength. ${ }^{1,2)}$ The further strengthening with reliability enhancement has been always expected. However, the high strength CFRP, whose supply often cannot catch up with demand exhibits a high cost.

Since CFRP sheets prevent crack generation near the CFRP/polymer interface, ${ }^{3)}$ sandwich structural composites (CFRP/ABS/CFRP and CFRP/PMMA/CFRP) of both acrylonitrile butadiene styrene (ABS) and poly methyl methacrylate (PMMA) resins cores covered with carbon fiber reinforced epoxy polymer (CFRP) sheets at both side surfaces have been suggested to reduce cost. The impact value, $a_{\mathrm{uc}}$ of $\mathrm{CFRP} / \mathrm{ABS} / \mathrm{CFRP},{ }^{3)}$ which approximately corresponds to that of CFRP composite, ${ }^{4)}$ is more than two times higher than that of CFRP/PMMA/CFRP. ${ }^{3)}$ In addition, since the price of CFRP $(84,000 \mathrm{Yen} / 1.0 \mathrm{~m} \times 1.0 \mathrm{~m} \times$ $2.0 \mathrm{~mm}$ at 2012 Feb.) is higher than that of ABS resin $(6240 \mathrm{Yen} / 1.0 \mathrm{~m} \times 1.0 \mathrm{~m} \times 2.0 \mathrm{~mm}$ at 2012 Feb.), the sandwich structural composites of CFRP/ABS/CFRP $(20,240$ Yen/ $1.0 \mathrm{~m} \times 1.0 \mathrm{~m} \times 2.0 \mathrm{~mm}$ at $2012 \mathrm{Feb}$. $)$ are only $24 \%$ that of CFRP, hence practical use is extremely required.

Figure 1 shows the structural formula of ABS monomer with its three groups. Thus, the high strength of sandwich structural composites of CFRP/ABS/CFRP can be expected.

*Graduate Student, Tokai University

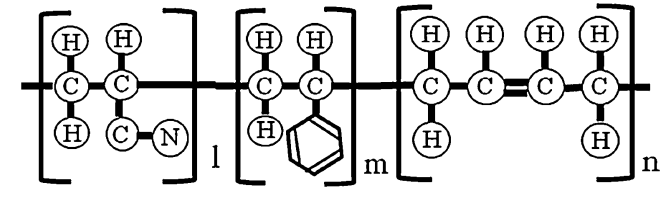

Fig. 1 Structural formula of acrylonitrile butadiene styrene (ABS).

In order to raise the impact value of CFRP/ABS/CFRP sandwich structures apparently more than that of CFRP alone, homogeneous low voltage electron beam irradiation (HLEBI) is employed. HLEBI is one of the possible tools to improve wear resistance, burnishing, change wetting, and sterilization. Since the stability and homogeneity of industrial HLEBI equipment are tremendously high, they have been practically utilized for wallpaper sheet, building insulation and automotive parts up to several square meters in size.

Although influences of electron beam (EB) irradiation with high potential energy on the fracture toughness of crossweave carbon fibers in thermo-hardened epoxy polymer matrix (thermo-hardened CFRP) have been well-reported, ${ }^{5)}$ no one has succeeded in strengthening of CFRP irradiated by electron beam with large dose as well as high potential energy.

On the other hand, the homogeneous low-voltage electron beam irradiation (HLEBI) often induces not only mist resistance, but also stiffness, high wear resistance and sterilization for practical use of polymer. ${ }^{6-8)}$ In addition, HLEBI has improved not only the bending fracture strain, 9,10 ) but also the deformation resistivity, tensile strength and strain of carbon fiber. ${ }^{11)}$ In order to utilize for high-speed transport 


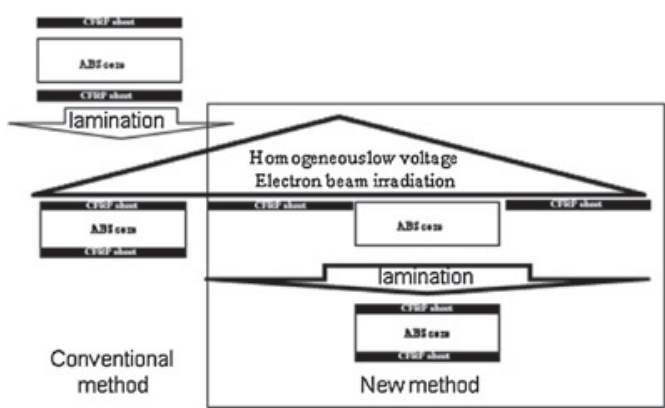

Fig. 2 Schematic diagram of sandwich structural (CFRP/ABS/CFRP) composites treated by HLEBI after (conventional) and before (new) lamination assembly.

vehicles, it has succeeded that the HLEBI also enhances the bending fracture stress, strain and impact value of CFRP. ${ }^{12,13)}$

Furthermore, the CFRP/ABS/CFRP sandwich structures have been successfully developed to reduce the cost to approximately $25 \%$ of CFRP. HLEBI applied to both side surfaces after assembly using the conventional method illustrated in the left of Fig. 2 perfectly improved the Charpy impact values $\left(a_{\mathrm{uc}}\right)$ of the sandwich structural composite polymers of laminated CFRP/ABS/CFRP composites due to surface CFRP sheet strengthening. ${ }^{14)}$ However, with increasing depth down to the CFRP-ABS interface, peeling is a serious issue for preventing fracture of laminated CFRP/ ABS/CFRP to insure aircraft safety.

To prevent the peeling, increased adhesive force between ABS and epoxy matrix in CFRP is required. Hence, the HLEBI induced adhesion between different polymers has been reported. ${ }^{15)}$ However, the CFRP sheet thickness of laminated CFRP/ABS/CFRP is $250 \mu \mathrm{m}$, which is larger than the irradiation penetration depth of $100 \mu \mathrm{m}$. To remedy this, HLEBI is applied to both side surfaces of the CFRP laminates and $\mathrm{ABS}$ core, respectively prior to lamination assembly into the CFRP/ABS/CFRP sandwich structure. This new method illustrated in Fig. 2 (right side) endeavors to improve the adhesive strength between ABS core and CFRP sheet as well as surface strengthening, resulting in increasing the impact values of the CFRP/ABS/CFRP.

Since the dangling bonds generated by the low-voltage electron beam act at bonding sites between carbon fiber and epoxy, HLEBI after lamination assembly is predicted to raise the impact value. In addition, if the effective bonding reaction period of dangling bonds as bonding sites among carbon fiber, epoxy and ABS has sufficiently long, HLEBI before lamination may be practical to improve the impact value. When the new method is succeeded, the strengthening of thick laminated CFRP/ABS/CFRP constructed with thick surface sheets and thick core can be expected. Therefore, the purpose of the present work is to investigate the effects of HLEBI before lamination assembly on impact value of CFRP/ABS/CFRP.

\section{Experimental Procedure}

\subsection{Condition of EB-irradiation}

The sheet samples were homogeneously treated by the prototype equipment known as the electron-curtain processor
(Type CB175/15/180L, Energy Science Inc., Woburn, MA), which was constructed with a vacuum chamber $(240 \mathrm{~mm}$ in diameter under $\left.10^{-5} \mathrm{~Pa}\right)$ with a tungsten filament $(215 \mathrm{~mm}$ length) and a thin titanium window (150 mm length, $150 \mathrm{~mm}$ width and $0.01 \mu \mathrm{m}$ thickness), and sample treatment compartment with conveyer under $1 \mathrm{~atm} \mathrm{~N}_{2(\mathrm{~g}) .}{ }^{5-13,16,17)}$

The sheet specimen was homogeneously irradiated with the electron beam through the titanium thin film window attached to the vacuum chamber. The tungsten filament in vacuum was used to generate the electron beam at a low energy (acceleration potential, $V: \mathrm{kV}$ ), of $170 \mathrm{kV}$ and irradiating current density $\left(J: \mathrm{A} \mathrm{m}^{-2}\right)$ of $0.089 \mathrm{~A} \mathrm{~m}^{-2}$. Although the electron beam generation was in a vacuum, the irradiated sample was kept under protective $1 \mathrm{~atm} \mathrm{~N}_{2(\mathrm{~g})}$. The distance between sample and window was $35 \mathrm{~mm}$. To prevent oxidation, the samples were kept in the protective $1 \mathrm{~atm} \mathrm{~N}_{2}$ with an $\mathrm{O}_{2}$ residual concentration below $400 \mathrm{ppm}$. The flow rate of the $\mathrm{N}_{2}$ was $1.5 \mathrm{~L} \mathrm{~s}^{-1}$ at $0.1 \mathrm{MPa}$ of $\mathrm{N}_{2}$ gas pressure.

Each sweep of irradiation dose (0.043 MGy $\left.\left(\mathrm{kJ} \mathrm{g}^{-1}\right)\right)$ was applied for only a short time $(0.23 \mathrm{~s})$ to avoid excessive heating of the sample; the temperature of the sample surface remained below $323 \mathrm{~K}$ just after irradiation. The sample in the aluminum plate holder $(0.15 \mathrm{~m} \times 0.15 \mathrm{~m})$ was transported on a conveyor at a speed of $10.0 \mathrm{~m} \mathrm{~min}^{-1}$. The sheet electron beam irradiation was applied intermittently. Repeated irradiations to both side surfaces of the samples were used to increase the total dose of irradiation. The interval between the end of one period of irradiation sweep and the start of the next was $30 \mathrm{~s}$.

When the irradiation current $(I: \mathrm{mA})$, the conveyor speed $\left(S: \mathrm{m} \mathrm{min}^{-1}\right)$, and number of irradiations $(N)$ are determined, the irradiated dose ( $D$ : MGy) is expressed by the following equation.

$$
D=0.216(I / S) N
$$

The irradiation dose was controlled by the integrated irradiation time in each of the samples. Here, irradiation dose was corrected by using FWT nylon dosimeter of RCD radiometer film (FWT-60-00: Far West Technology, Inc. 330-D South Kellogg Goleta, California 93117, USA) with irradiation reader (FWT-92D: Far West Technology, Inc. 330-D South Kellogg Goleta, California 93117, USA). The dose was $0.0432 \mathrm{MGy}$ at each irradiation.

As shown in Fig. 2, the new method proposed is treating the layers of CFRP and ABS on both side surfaces by HLEBI prior to lamination assembly, as an advance over the conventional method of treating the assembled CFRP/ ABS/CFRP on both CFRP outside surfaces only.

\subsection{Sample preparation}

The volume of sandwich structural composites of CFRP/ ABS/CFRP was $2000 \mathrm{~mm}^{3}$ consisting of: ABS core $\left(2.0 \times 80 \times 10=1600 \mathrm{~mm}^{3}\right.$, SECON MIKI INDUSTRY INC, Tokyo) covered with 1 ply of carbon fiber cross textile reinforced epoxy polymer (CFRP) thin sheets at both side surfaces $\left(0.25 \times 80 \times 10=200 \mathrm{~mm}^{3}\right.$, TR3110-331MP epoxy/CF, Mitsubishi Rayon Ltd., Tokyo) was $2000 \mathrm{~mm}^{3}$. The CFRP sheets and ABS cores were separately treated by HLEBI before lamination assembly. The CFRP/ABS/CFRP 
laminate sample was pre-preged. Volume fraction, $V_{\mathrm{f}}$ of carbon fiber and ABS core were 12 and $88 \mathrm{vol} \%$, respectively. In the CFRP sheet, $V_{\mathrm{f}}$ of carbon fiber was $60 \%$. Composite samples were fabricated by autoclave molding in vacuum under $1 \mathrm{~Pa}$ for $2 \mathrm{~h}$ at $403 \mathrm{~K}$.

\subsection{Impact test and conditions}

Traditionally, damage by a hemispherical impactor is initiated as a point force on the center of a square or rectangular specimen $\sim 70$ to $150 \mathrm{~mm}^{2}$ by slow point force, ${ }^{18)}$ drop tower, or projectile. ${ }^{19-22)}$ For low energy tests, impact is followed by non-destructive testing (NDT) with an ultrasonic transducer to detect delamination undetectable to the eye which can strength significantly. Compression after impact (CAI) testing is often conducted after point impact in aerospace materials such as quasiisotropic CFRP for safety design. ${ }^{23,24)}$ Five fracture modes in composite laminates and sandwich panels undergoing point impact have been identified: core crushing, core cracking, delamination in the impacted face sheet, matrix cracking, and fiber breakage in the face sheets. ${ }^{25}$ ) This method of point impact fracture followed by CAI for aircraft CFRP has been generally studied to evaluate safety against impact accidents such as bird strike, volcanic rock or hailstone on aircraft CFRP. ${ }^{26,27)}$ On the other hand, the Charpy impact test utilizes a dropweight pendulum and evaluates the impact absorption characteristics and relative impact toughness of materials often used in quality control applications employed as an inexpensive and fast way to estimate reaction to higher velocity impact. We do not claim the Charpy test to be a substitute for point impact followed by compression after impact (CAI). However, Charpy impact method could possibly be used as an inexpensive preliminary evaluation to screen candidate materials to later test with indentation or projectile followed by CAI. Hence, Charpy may give a rough or better estimation of which materials and what temperatures a projectile such as bird strike, volcanic rock or hailstone will cause the most damage. Tests are carried out calibrating for air friction and effect of air temperature and humidity on the swing and pivot of the pendulum. Therefore the velocity, $v\left(\mathrm{~ms}^{-1}\right)$ and kinetic energy, $K E(\mathrm{~J})$ hitting the sample are assumed to be approximately constant similar to comparing projectiles in a point impact test hitting the composite surface at constant $v$ and $K E$. Thus, when the Charpy impact test impact velocity, $v$ hitting the sample is calculated as: ${ }^{28)}$

$$
v=[2 g R(1-\cos \alpha)]^{0.5}
$$

where $g$ is gravitational constant $\left(9.8 \mathrm{~m} \mathrm{~s}^{-2}\right), R$ is length (m) of hammer weight point from rolling center $(0.21 \mathrm{~m})$, and $\alpha$ is start angle before impact $\left(2.3\right.$ Radians, $\left.132^{\circ}\right)$, then $v$ of the hammer hitting the specimen is $\sim 1.74 \mathrm{~m} \mathrm{~s}^{-1}(\sim 3.89 \mathrm{mi} / \mathrm{hr})$. Potential energy $(P E)(\mathrm{J})$ of impact is: ${ }^{28)}$

$$
P E=R(1-\cos \alpha) F
$$

where $F$ is the measured supporting force $(\mathrm{N})$ exerted by the pendulum in the horizontal position. $P E$ is assumed to be equivalent to the $K E$ in the horizontal vector, $0.5 m v^{2}$, or $1.30 \mathrm{~J}\left(1.3 \times 10^{-3} \mathrm{~kJ}\right)$. The surface area of the impactor is small so $K E / A$ is large.
In order to evaluate the impact fracture toughness, the Charpy impact values of the CFRP/ABS/CFRP and CFRP samples using a standard impact fracture energy measurement system (Shimadzu Corporation No. 51735) (JIS K 7077) was utilized. ${ }^{13,16,17)}$ The cross-weave CFRP sheets of $\sim 80 \times 160 \times 0.25 \mathrm{~mm}$ (1-ply); and ABS core of $\sim 80 \times$ $160 \times 2 \mathrm{~mm}$ were separately HLEBI irradiated on both side surfaces, then adhered together into the CFRP/ABS/CFRP sandwich structures with ABS in between the 2 CFRP plies, and subsequently cut according to JIS K 7077 specification $80 \times 10 \times 2.5 \mathrm{~mm}$ (total thickness $=2.5 \mathrm{~mm}$ ) dimensions .

The impact fracture energy $(E)$ is expressed by the following equation. ${ }^{13,16,17)}$

$$
\begin{aligned}
E= & W R[(\cos \beta-\cos \alpha) \\
& \left.-\left(\cos \alpha^{\prime}-\cos \alpha\right)(\alpha+\beta) /\left(\alpha+\alpha^{\prime}\right)\right]
\end{aligned}
$$

Here, $E, W, R, \beta, \alpha$ and $\alpha^{\prime}$ are impact fracture energy $(\mathrm{J})$, hammer weight $(8.43 \mathrm{~N})$, length $(\mathrm{m})$ of hammer weight point from rolling center $(0.21 \mathrm{~m})$, the maximum angle after impact, start angle before impact $\left(132^{\circ}\right)$, and the maximum angle of the blank test (Radians), respectively. The Charpy impact value $\left(a_{\mathrm{uc}}: \mathrm{kJ} \mathrm{m}^{-2}\right)$ is expressed by the following equation. $^{22)}$

$$
a_{\mathrm{uc}}=E /(b t) \times 10^{3}
$$

Here, $E, b(=10 \pm 0.2 \mathrm{~mm})$ and $t(=2.8 \mathrm{~mm})$ are impact fracture energy $(\mathrm{J})$, sample width $(\mathrm{mm})$ and span distance (sample thickness, mm), respectively. The distance between supporting points was $40 \mathrm{~mm}$.

\subsection{Evaluation of dangling bonds}

To obtain more precise information on atomic-scale structural changes in the ABS, the density of the dangling bonds was measured by means of an ESR spectrometer (JESFA2000, Nippon Denshi Ltd., Tokyo). ${ }^{11,16,17)}$ The microwave frequency range used in the ESR analysis was the X-band at $9.45 \pm 0.05 \mathrm{GHz}$ with a field modulation of $100 \mathrm{kHz}$. The microwave power was $1 \mathrm{~mW}$. The magnetic field was varied from 317-327 $\mathrm{mT}$. The spin density was calculated by using the $\mathrm{Mn}^{2+}$ standard sample. Only ESR spectra are given, not spin densities. Based on the standard calibration material [4-hydroxy-2,2,6,6-tetra-methylpiperidine-1-oxyl (TEMPOL, 089-04191, Wako Pure Chemical Industries Ltd., Tokyo)] and $\mathrm{Mn}^{2+}$ in the $\mathrm{MnO}$, the density of dangling bonds is estimated by double integration of the intensity of the ESR signal.

\section{Results}

\subsection{Effects of HLEBI on impact values of CFRP/ABS/ CFRP}

Evaluating the probability of fracture $\left(P_{\mathrm{f}}\right)$ is a convenient method of quantitatively analyzing experimental values relating to fracture. $P_{\mathrm{f}}$ is expressed by the following equation, which is a generalized form of the median rank method: ${ }^{29)}$

$$
P_{\mathrm{f}}=(i-0.3) /\left(N_{\mathrm{s}}+0.4\right)
$$

where $N_{\mathrm{s}}$ and $i$ are the total number of samples $\left(N_{\mathrm{s}}=11\right.$ for HLEBI treated, and 22 for untreated) and the order of fracture of each sample, respectively. Here, the order of fracture is the 


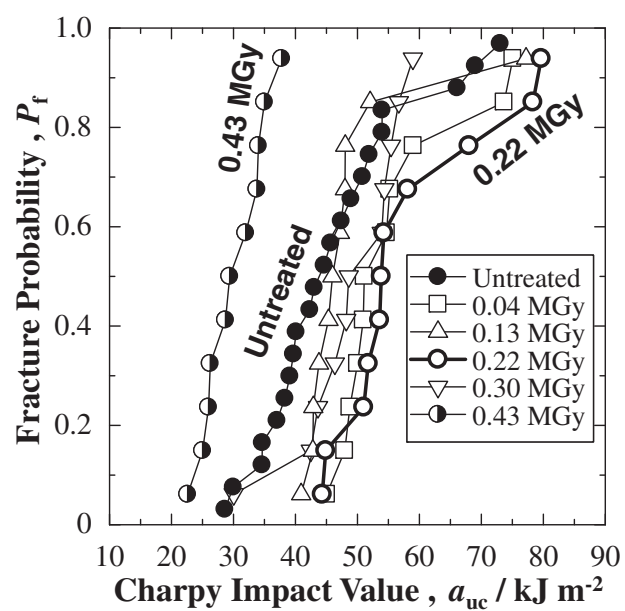

Fig. 3 Relationships between Charpy impact value $\left(a_{\mathrm{uc}}\right)$ of CFRP/ABS/ CFRP whose surfaces were EB irradiated prior to lamination assembly, and fracture probabilities $\left(P_{\mathrm{f}}\right)$ as a function of EB dose.

aligned number of fractured samples from low to high impact value. For the $N_{\mathrm{s}}=11$ HLEBI-treated, when the $i$ values are 1, 6 and 11, the $P_{\mathrm{f}}$ values are $0.06,0.50$ and 0.94 , respectively.

Figure 3 shows effects of applying HLEBI to both side surfaces of the CFRP/ABS/CFRP layers prior to lamination assembly, where the doses of 0.04 or $0.22 \mathrm{MGy}$ apparently improved Charpy impact values, $a_{\mathrm{uc}}$ at all $P_{\mathrm{f}}$. The $0.22 \mathrm{MGy}$ HLEBI showed the most improvement: average $a_{\mathrm{uc}}$ was raised $20 \%$ from 44 to $53 \mathrm{~kJ} \mathrm{~m}^{-2}$. Moreover for the $0.22 \mathrm{MGy}$ HLEBI, at $P_{\mathrm{f}}=0.83 a_{\mathrm{uc}}$ is boosted $47 \%$ from 53 to $78 \mathrm{~kJ} \mathrm{~m}^{-2}$. Also the lower dose of $0.04 \mathrm{MGy}$ HLEBI raised the average $a_{\mathrm{uc}} 15 \%$ from 44 to $51 \mathrm{~kJ} \mathrm{~m}^{-2}$. Although the 0.30 MGy HLEBI apparently decreased the $a_{\mathrm{uc}}$ at low $P_{\mathrm{f}}=0.05$ and high $P_{\mathrm{f}}>0.82$, the 0.30 dose improved $a_{\mathrm{uc}}$ at $0.10<P_{\mathrm{f}}<0.82$. Likewise, while the 0.13 dose reduced $a_{\mathrm{uc}}$ at the higher $0.65<P_{\mathrm{f}}<0.90$, the 0.13 dose improved $a_{\text {uc }}$ at $0.05<P_{\mathrm{f}}<0.60$ and $P_{\mathrm{f}}>0.90$. It is noted here the higher dose of $0.43 \mathrm{MGy}-\mathrm{HLEBI}$ reduces the $a_{\mathrm{uc}}$ values at all experimental fracture probability $\left(P_{\mathrm{f}}\right)$, and is tremendously lower than that without HLEBI.

Figure 4 shows changes in Charpy impact value $\left(a_{\mathrm{uc}}\right)$ at $P_{\mathrm{f}}$ of $0.06,0.50$ and 0.94 of CFRP/ABS/CFRP against dose of HLEBI before $(\bigcirc, \square, \triangle)$ compared with that from a previous study after lamination ${ }^{4}(\mathbf{\bullet}, \mathbf{\square}, \mathbf{\Delta})$, respectively. HLEBI from 0.04 to $0.22 \mathrm{MGy}-\mathrm{HLEBI}$ before lamination raises the $a_{\mathrm{uc}}$ values at mid $P_{\mathrm{f}}(0.50)$ of the CFRP/ABS/CFRP. The maximum $a_{\mathrm{uc}}$ value $\left(53.8 \mathrm{~kJ} \mathrm{~m}^{-2}\right)$ at mid $P_{\mathrm{f}}(0.50)$ after $0.22 \mathrm{MGy}$ irradiation for the CFRP/ABS/CFRP is approximately $23.4 \%$ higher than that without $\operatorname{HLEBI}\left(43.6 \mathrm{~kJ} \mathrm{~m}^{-2}\right)$. Moreover, the $a_{\mathrm{uc}}$ values at each $P_{\mathrm{f}}$ of $0.06,0.50$ and 0.94 at small dose of HLEBI from 0.04 to $0.22 \mathrm{MGy}$ before lamination were always higher than those after lamination. Thus, employing the new process with HLEBI from 0.04 to $0.22 \mathrm{MGy}$ appears to prove effective.

\subsection{Optical observation of fractured CFRP/ABS/CFRP as a function of HLEBI dose}

Figure 5 shows photographs of fractured CFRP/ABS/ CFRP samples from the HLEBI applied before laminate

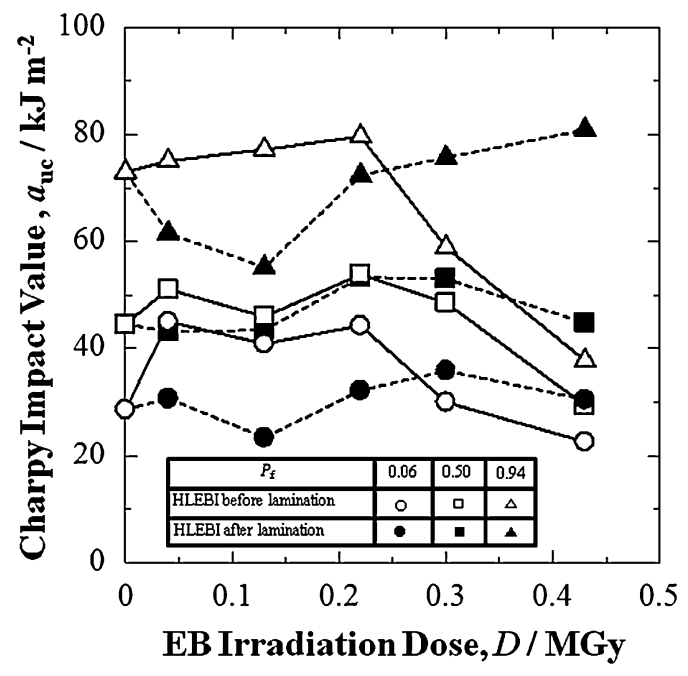

Fig. 4 Changes in Charpy impact value $\left(a_{\mathrm{uc}}\right)$ at $P_{\mathrm{f}}$ of $0.06,0.50$ and 0.94 of CFRP/ABS/CFRP against HLEBI dose before $(\bigcirc, \square, \triangle)$ and after lamination $(\mathbf{O}, \mathbf{\square}, \mathbf{\Delta})$, respectively.

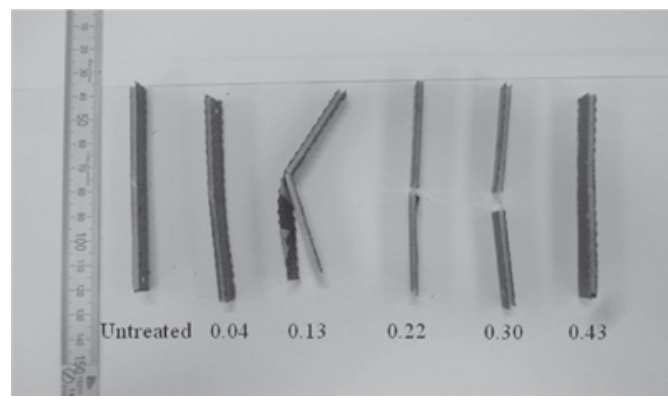

$P_{\mathrm{f}}=\mathbf{0 . 0 6}$

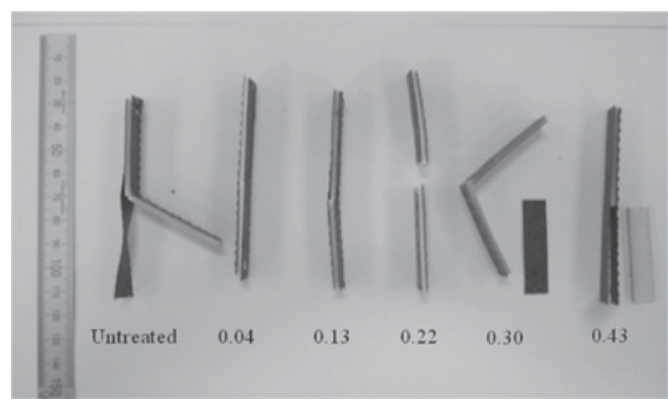

$P_{\mathrm{f}}=\mathbf{0 . 5 0}$

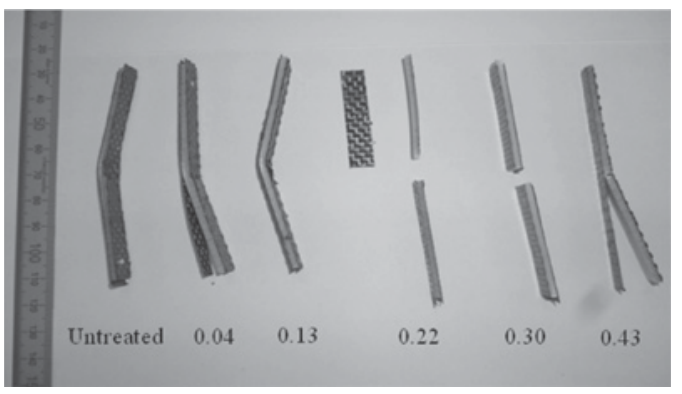

$P_{\mathrm{f}}=\mathbf{0 . 9 4}$

Fig. 5 Photograph of fractured CFRP/ABS/CFRP samples at each $P_{\mathrm{f}}$ as a function of HLEBI dose. 
Table 1 Fracture mode, impact value $\left(\mathrm{kJ} \mathrm{m}^{-2}\right)$ and reduced delamination area against sheet sample area at low, mid- and high fracture probability. $\left(P_{\mathrm{f}}=0.06,0.50\right.$ and 0.94$)$ at each EB irradiation of $0.04,0.13,0.22,0.30$ and $0.43 \mathrm{MGy}$, respectively. $\bigcirc$ and $\bigcirc$ are delamination at CFRP sheets at impact side and tensile sides, respectively. $\diamond$ and $\diamond$ are ABS core with bending fracture and bending plastic deformation, respectively. $\square$ is complete bending fracture of one or more constituents.

\begin{tabular}{ccccccc}
\hline \multirow{2}{*}{$P_{\mathrm{f}}$} & \multicolumn{7}{c}{ HLEBI before lamination } \\
\cline { 2 - 7 } & Untreated & 0.04 & 0.13 & 0.22 & 0.30 & 0.43 \\
\hline \multirow{2}{*}{0.06} & $\bigcirc \diamond$ & $\bigcirc \diamond$ & $\bigcirc \diamond$ & $\diamond \square$ & $\diamond \square$ & $\bigcirc \diamond$ \\
& 28.6 & 45.0 & 40.9 & 30.8 & 30.0 & 22.6 \\
\hline \multirow{2}{*}{0.50} & $\bigcirc \diamond$ & $\bigcirc \diamond$ & $\bigcirc \diamond$ & $\diamond \square$ & $\bigcirc \diamond$ & $\diamond \square$ \\
& 44.6 & 51.0 & 45.9 & 40.2 & 48.5 & 29.3 \\
\hline \multirow{2}{*}{0.94} & $\bigcirc \diamond$ & $\bigcirc \diamond$ & $\bigcirc \diamond$ & $\bigcirc \square$ & $\diamond \square$ & $\bigcirc$ \\
& 73.0 & 75.0 & 77.2 & 57.8 & 58.9 & 37.7 \\
\hline
\end{tabular}

assembly as a function of HLEBI dose. Fracture modes are summarized in Table 1. Notably bending fracture occurs for HLEBI dose greater than or equal to $0.22 \mathrm{MGy}$ at the low (0.06), middle (0.50) and high (0.94) $P_{\mathrm{f}}$. Peeling fracture (delamination) between CFRP sheets and ABS core is always observed in specimens treated at small dose up to $0.13 \mathrm{MGy}-$ HLEBI.

From 0.22 to $0.43 \mathrm{MGy}-\mathrm{HLEBI}$ doses, the peeling fracture is observed to a lesser extent in the CFRP/ABS/CFRP samples, (Fig. 5) showing complete bending fracture of one or more constituents (either the core, CFRP or both) becoming dominant.

On the other hand, observed data from HLEBI applied after laminate assembly ${ }^{4}$ showed simple bending fracture occurs from the 0.22 to $0.43 \mathrm{MGy}-\mathrm{HLEBI}$ doses. Regardless if samples were from the HLEBI applied before or after the laminate assembly, it should be confirmed that the complete bending fractures of ABS core and CFRP sheet with pull-out of carbon fiber from epoxy resin are mostly observed at the impact point in fractured CFRP/ABS/CFRP irradiated with 0.22 and $0.30 \mathrm{MGy}$ at each $P_{\mathrm{f}}$ value. The weakest point of the simple fracture, therefore is the bending fracture of ABS core, as well as CFRP sheets.

\section{Discussion}

\subsection{Effects of HLEBI before lamination on impact values of CFRP/ABS/CFRP}

During impact of CFRP laminates, fracture of the outer CFRP ply can be viewed as a stepwise fracture mechanism. First, the main cracks generate at the tensile surface and propagate perpendicular to the impact force at the interface between fiber and matrix.

This occurs until there is enough tensile force on the next neighboring carbon fibers to fracture, which marks the end of the cycle. These cycles subsequently repeat until the entire thickness of this outer CFRP ply fractures. Next depending on the adhesive strength between plies, either delamination, and/or further cracking through the specimen will dominate. Since impact is a surface-sensitive test, this mechanism also holds true for sandwich structure CFRP/ABS/CFRP whose outer layers are a single ply of CFRP. In this material, fracture

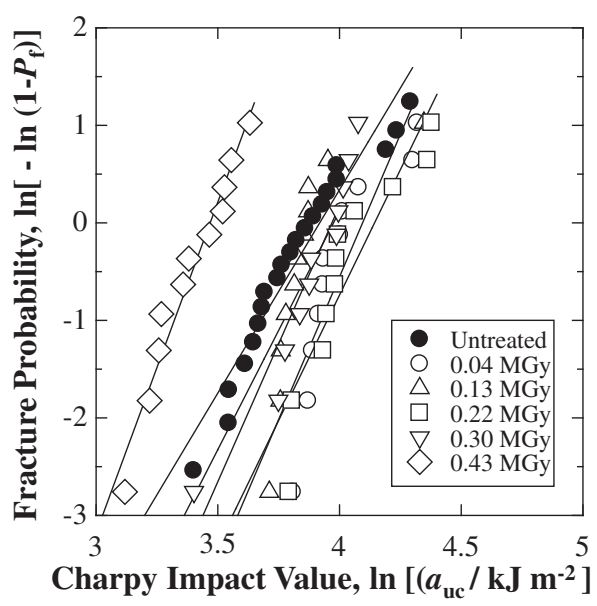

Fig. 6 Weibull coefficients of CFRP/ABS/CFRP at each dose of HLEBI, for conditions of HLEBI before (unfilled points $\bigcirc$ ) and after lamination assembly.

also begins with breakage of the carbon fibers on the tensile side. However, as the single one ply of CFRP fractures, due to shear force brought about by difference in modulus of CFRP and ABS, the weakest point next becomes the peeling fracture of the ABS/epoxy interface, due to shear force brought about by difference in modulus of CFRP and ABS.

Since this peeling of CFRP sheet probably relaxes the impact energy, the high impact value of CFRP/ABS/CFRP is probably caused by not only total fractured surface energy but also effects of HLEBI on the impact value of the carbon fiber, epoxy, ABS and their interface. HLEBI generates dangling bonds creating microcompressive forces increasing adhesive strength of many structural materials ${ }^{15}$ ) therefore increasing resistance to impact.

\subsection{Weibull coefficient ( $n$ ) of CFRP/ABS/CFRP}

The 2-parameter Weibull coefficient $(n)$ is one of the standard and traditional factors to compare with the database of structural materials. ${ }^{30)}$ When $a_{\mathrm{uc}}$ is the measured Charpy impact value and $a_{\mathrm{o}}$ is a constant, the fracture probability $\left(P_{\mathrm{f}}\right)$ as a function of the risk of rupture $\left(a_{\mathrm{uc}} / a_{\mathrm{o}}\right)$ is expressed by the following equation. ${ }^{30)}$

$$
P_{\mathrm{f}}=1-\exp \left[-\left(a_{\mathrm{uc}} / a_{\mathrm{o}}\right)^{n}\right]
$$

The linear relationship can be obtained as the following equation.

$$
\ln \left(-\ln \left(1-P_{\mathrm{f}}\right)\right)=n \ln a_{\mathrm{uc}}-n \ln a_{\mathrm{o}}
$$

Figure 6 shows Weibull plots of CFRP/ABS/CFRP at each dose of HLEBI. The $n$ value corresponds to the slopes of the relationships of Weibull plots, higher slope is higher experimental reliability. Figure 7 shows the change in $n$ of impact value of CFRP/ABS/CFRP against HLEBI dose before $(\bigcirc)$ and after $(\bullet)$ lamination assembly.

Although HLEBI applied after lamination from 0.04 to 0.43 MGy gradually reduces $n$ (bottom curve), HLEBI applied before lamination tremendously enhances $n$ (top curve). The $n$ values of CFRP/ABS/CFRP from 0.04 to 0.43 MGy-HLEBI applied before lamination (4.8-6.7) are always higher than that (4.0-5.1) of HLEBI applied after 


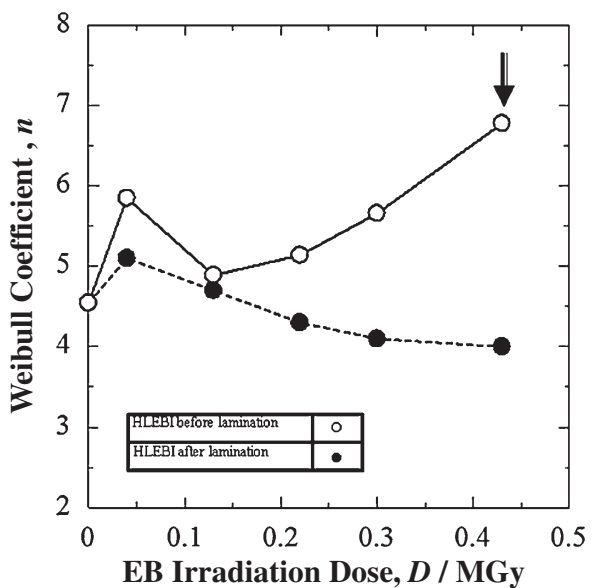

Fig. 7 Changes in Weibull coefficient $(n)$ of CFRP/ABS/CFRP against dose of HLEBI before $(\bigcirc)$ and after lamination $(\mathbf{)})$.

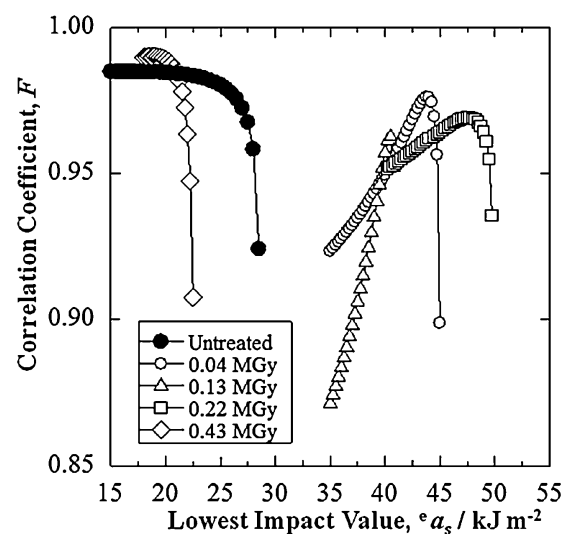

Fig. 8 Changes in the $\mathrm{F}$ value of $\mathrm{CFRP} / \mathrm{ABS} / \mathrm{CFRP}$ at each dose of HLEBI against the lowest impact value candidate.

lamination. In brief, the new method of HLEBI applied prior to lamination improves the reproducibly over the other conditions.

\subsection{The lowest limit of impact value, $a_{\mathrm{s}}$ estimated at $\boldsymbol{P}_{\mathrm{f}}=\mathbf{0}$ by three parameter Weibull equation}

On the other hand, since the experimental impact values at lower $P_{\mathrm{f}}$ value have largely deviated from the linear relationship (see Fig. 3), the practical impact value at low $P_{\mathrm{f}}$ cannot be precisely estimated.

If the statistical equation is assumed to be applicable to the measured $a_{\mathrm{uc}}$ value, the $P_{\mathrm{f}}$ value depends on the risk of rupture $\left(\left[a_{\mathrm{uc}}-a_{\mathrm{s}}\right] / a_{\mathrm{III}}\right){ }^{26,30)}$

$$
P_{\mathrm{f}}=1-\exp \left[-\left(\left[a_{\mathrm{uc}}-a_{\mathrm{s}}\right] / a_{\mathrm{III}}\right)^{m}\right]
$$

In predicting the required impact value of a new structural material, the lowest impact value $\left(a_{\mathrm{s}}\right)$, the 3-parameter Weibull coefficient $(m)$ and constant $\left(a_{\mathrm{III}}\right)$ are key parameters. While the $a_{\mathrm{III}}$ is the $a_{\mathrm{uc}}$ value at $P_{\mathrm{f}}$ of 0.632 when the term $\left(\ln \left[-\ln \left(1-P_{\mathrm{f}}\right)\right]\right)$ is zero, the $a_{\mathrm{s}}$ value is defined as the $a_{\mathrm{uc}}$ value when $P_{\mathrm{f}}=0$ and represents the statistically lowest possible impact value for safety considerations and deems valuable for quality control. Figure 8 shows iteration of the potential lowest impact value ( ${ }^{\mathrm{e}} a_{\mathrm{s}}$ ) in the linear logarithmic form of eq. (9) to obtain the maximum correlation coefficient

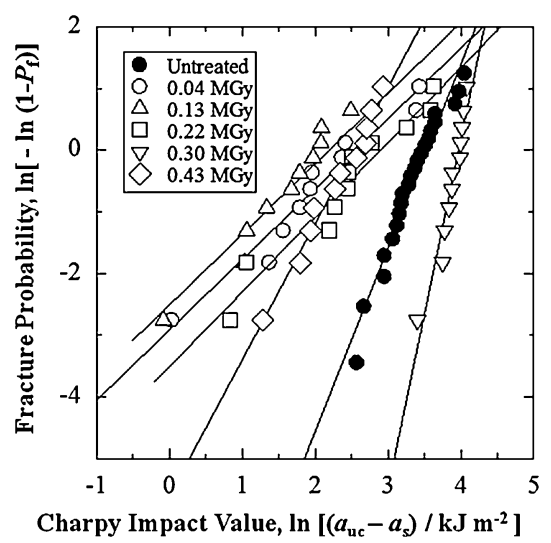

Fig. 9 Liner relationships between $\ln \left(a_{\mathrm{uc}}-a_{\mathrm{s}}\right)$ and $\ln \left[-\ln \left(1-P_{\mathrm{f}}\right)\right]$ for CFRP/ABS/CFRP at each dose of HLEBI.

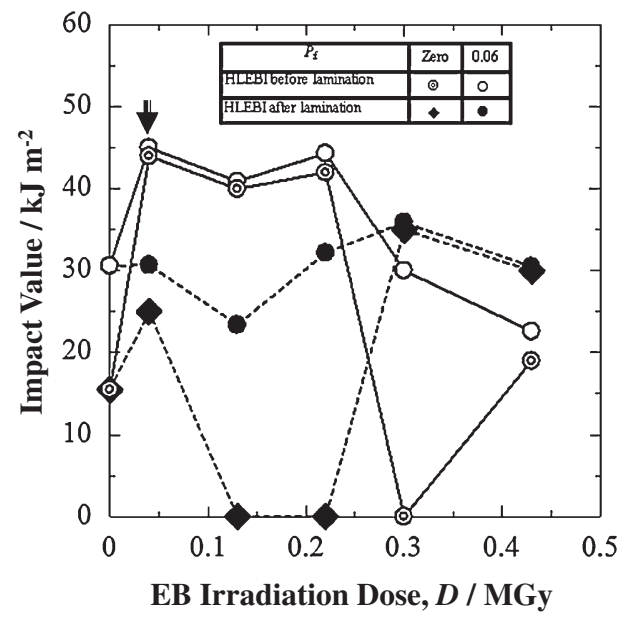

Fig. 10 Changes in lowest impact values (@), $\diamond: a_{\mathrm{s}}=a_{\mathrm{uc}}$ at $P_{\mathrm{f}}=0$ ); and experimental impact values $\left(a_{\mathrm{uc}}: \bigcirc, \bigcirc\right)$ at low $P_{\mathrm{f}}$ of 0.06$)$ of CFRP/ABS/ CFRP against dose of HLEBI before $(\odot, \bigcirc)$ and after lamination $(\diamond, \bigcirc)$, respectively.

$(F)$ corresponding to the $a_{\mathrm{s}}$ (arrows) showing high linear correlations between 0.96 and 0.99 whose linear relationships are plotted in Fig. 9. Figure 10 compares changes in the lowest impact values estimated (๑, $\diamond: a_{\mathrm{s}}=a_{\mathrm{uc}}$ at $\left.P_{\mathrm{f}}=0\right)$ and experimental impact values $\left(a_{\mathrm{uc}}: \bigcirc\right.$, ๑: at low $P_{\mathrm{f}}$ of 0.06$)$ of CFRP/ABS/CFRP plotted against HLEBI dose before $(\odot, \bigcirc)$ and after lamination $(\diamond, \bullet)$, respectively. When the lowest limit of impact value $\left(a_{\mathrm{s}}\right)$ calculated by the 3-parameter Weibull eq. (9) and experimental results is $a_{\mathrm{uc}}$ at the lowest $P_{\mathrm{f}}$ value of zero the plot in Fig. 10 is obtained.

Although carefulness for aircraft parts would be necessary since Fig. 10 shows higher doses of 0.30 and $0.43 \mathrm{MGy}$ HLEBI applied to the CFRP sheets and ABS core before lamination assembly reduce the $a_{\mathrm{s}}$; the low dose of 0.04 MGy-HLEBI before lamination assembly apparently boosts the $a_{\text {s }}$ almost 3 times, $\sim 200 \%$, over the untreated samples from 15 to $44 \mathrm{~kJ} \mathrm{~m}^{-2}$ (Fig. 10, arrow). Moreover, applying the low dose of $0.04 \mathrm{MGy}-\mathrm{HLEBI}$ before instead of after lamination apparently improves the $a_{\mathrm{s}} 76 \%$ from 25 to $44 \mathrm{~kJ} \mathrm{~m}^{-2}$. Furthermore, applying the medium doses of $0.13 \mathrm{MGy}$ or $0.22 \mathrm{MGy}$ HLEBI before rather than after lamination appears to improve the $a_{\mathrm{s}}$ remarkably from 0 to 40 , and 0 to $42 \mathrm{~kJ} \mathrm{~m}^{-2}$, respectively. 
As for the experimental data at low $P_{\mathrm{f}}=0.06$, applying the low dose 0.04 MGy-HLEBI before instead of after lamination apparently improves the $a_{\mathrm{uc}} 40 \%$ from 31 to $46 \mathrm{~kJ} \mathrm{~m}^{-2}$.

In addition, applying the medium doses of 0.13 or 0.22 MGy-HLEBI before rather than after lamination appears to improve the $a_{\mathrm{uc}}$ at low $P_{\mathrm{f}}=0.06$ from 24 to $42(75 \%)$ and 32 to $44 \mathrm{~kJ} \mathrm{~m}^{-2}(37 \%)$, respectively.

Again, the higher doses of 0.30 and 0.43 MGy HLEBI reduce the $a_{\mathrm{s}}$, and $a_{\mathrm{uc}}$ at $P_{\mathrm{f}}=0.06$.

Compared to treatment after lamination, since both surface sides of CFRP sheets and ABS core have been separately irradiated by electron beam with the low voltage of $100 \mathrm{keV}$ class before lamination, the microcompressive stresses were generated between matrix and fiber and within the ABS matrix itself more efficiently, strengthening the CFRP sheets and ABS core, respectively. Thus deeper areas could be treated. More importantly, the HLEBI applied to both side surfaces prior to lamination probably increased the adhesive interface between ABS core and CFRP sheets. Thus, both the internal and external processes probably acted in concert to improve the $a_{\mathrm{uc}}$, when applied prior to lamination.

Since the $a_{\mathrm{s}}$ values from 41 to $44 \mathrm{~kJ} \mathrm{~m}^{-2}$ at small dose of HLEBI from 0.04 to $0.22 \mathrm{MGy}$ before lamination were always higher than that without HLEBI after lamination, the irradiation dose of the new process from 0.04 to $0.22 \mathrm{MGy}$ is in the safety zone as well as effective.

Major difference between the new (HLEBI before lamination) and conventional (HLEBI after lamination) methods is gas contamination concentration. The contamination cannot be remarkably detected at the CFRP-ABS interface in the conventional method. When oxygen atoms absorbed the terminated atoms with dangling bonds of ABS and epoxy in the new method, $a_{\mathrm{uc}}$-improvement by small dose of HLEBI from 0.04 to 0.22 MGy can probably be explained by the highly electronegative oxygen atoms as dangling bonds assisting in stronger bonding between the CFRP and ABS surfaces.

\subsection{Impact value induced by adhesion and strength- ening}

Figure 11 shows ESR signals of ABS resin before and after HLEBI. Spontaneous dangling bonds have been observed in untreated ABS polymers, as well as carbon fiber, ${ }^{10)}$ whereas the dangling bonds in epoxy treated by HLEBI have been also found. ${ }^{3)}$ Since dangling bond densities in carbon fiber, ${ }^{10)}$ epoxy ${ }^{10)}$ and ABS polymers (see Fig. 11) have been controlled by HLEBI dose, it is possible to get optimum density of dangling bonds for adhesion.

Figure 12 shows schematic illusions of chemical and intermolecular bonding sites at interface between carbon fiber and epoxy (a) and between ABS and epoxy (b). When HLEBI cuts the chemical bonds and generated dangling bonds with nonbonding electrons in epoxy polymers, the electrons probably induce the chemical bonding and intermolecular attractive force. HLEBI inducing strong adhesive force was explained by the chemical bonds and inter-molecular forces between carbon fiber and epoxy (see Fig. 12(a)) and between epoxy and ABS (see Fig. 12(b)). Therefore, it was concluded that HLEBI was a useful tool for quick lamination of CFRP/ABS/CFRP.

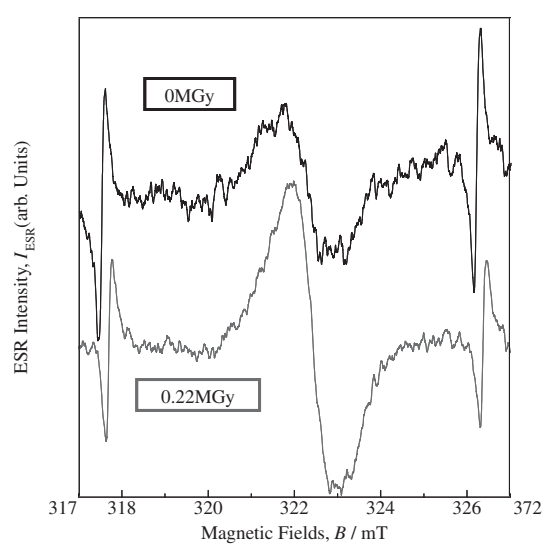

Fig. 11 ESR signals of ABS resin before and after HLEBI.

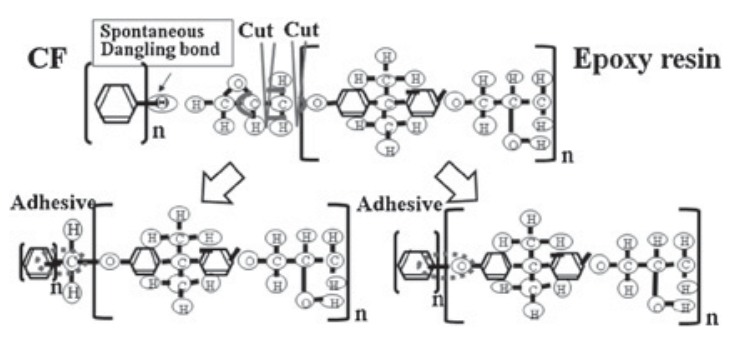

(a) Interface between CF and epoxy
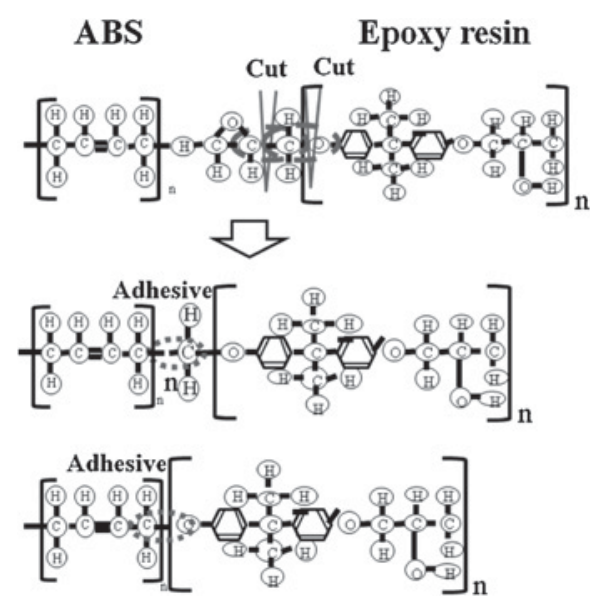

(b) Interface between $\mathrm{ABS}$ and epoxy

Fig. 12 Schematic illusion of chemical and intermolecular bonding sites at interface between carbon fiber and epoxy (a) and between ABS and epoxy (b).

Since the dangling bonds are generated by HLEBI (see Fig. 12), they act as bonding sites to terminated atoms by coulomb attractive force at the adhesive interface among epoxy, ABS and carbon fiber. Thus, the high impact value of CFRP/ABS/CFRP sandwich structural composite (Figs. 4 and 10) can be explained by adhesion force of ABS/epoxy and epoxy/carbon fiber, as well as strengthening carbon fiber, epoxy and ABS. Strengthening carbon fiber and epoxy has been reported. ${ }^{14)}$ Since smaller doses of HLEBI often improve mechanical properties, it is possible that it does not reduce other mechanical properties. In addition, HLEBI commonly inducing adhesive force between different polymers has been observed at interfaces of PTFE/PE, PTFE/PU, and PTFE/PDMS, as well as nylon6/silicone rubber, nylon6/PE and rubber nylon6/PP. ${ }^{15)}$ 
While additional dangling bonds generated by HLEBI above 0.43 MGy probably act as crack origins and propagation sites internally and at the laminated interface, the HLEBI at the 0.30 to 0.43 MGy range probably degrades the materials on a molecular level reducing $a_{\mathrm{uc}}$ (see Figs. 4 and 10).

Furthermore, the electrons probably induce the polarization at terminated atoms of materials at the adhesive interface. In addition, the additional dose of HLEBI enhances the density of dangling bonds. However, when the density exceeds a certain limit characteristic of the target material, the intermolecular attractive forces seem to reduce, resulting in decay of $a_{\mathrm{uc}}$ (see Figs. 4 and 10). Although HLEBI is shown to enhance impact values remarkably in the CFRP/ABS CFRP sandwich structures, carefulness is recommended in industry quality control to adjust the HLEBI dose to optimum level when treating aircraft parts to maximize safety and strength.

\section{Conclusion}

The sandwich structural composites (CFRP/ABS/CFRP) of acrylonitrile butadiene styrene (ABS) core covered with single ply sheets of carbon fiber cross textile reinforced epoxy (CFRP) at both side surfaces separately irradiated by homogeneous low voltage electron beam irradiation (HLEBI) before lamination were prepared. The materials cost of CFRP/ABS/CFRP is $25 \%$ of CFRP.

(1) The $a_{\mathrm{uc}}$ values at each $P_{\mathrm{f}}$ of CFRP/ABS/CFRP separately irradiated from 0.04 to $0.30 \mathrm{MGy}-\mathrm{HLEBI}$ before lamination were mostly higher than that without HLEBI.

(2) Although carefulness for aircraft parts would be necessary since higher doses of 0.30 and 0.43 MGy HLEBI applied to the CFRP sheets and ABS core before lamination assembly reduced $a_{\mathrm{s}}$, the low dose of $0.04 \mathrm{MGy}-\mathrm{HLEBI}$ before lamination assembly apparently boosted the $a_{\mathrm{s}}$ almost 3 times, $\sim 200 \%$, over the untreated samples.

(3) Moreover, applying the low dose of 0.04 MGy-HLEBI before instead of after lamination apparently improved the $a_{\mathrm{s}} 76 \%$ from 25 to $44 \mathrm{~kJ} \mathrm{~m}^{-2}$. Furthermore, applying the medium doses of $0.13 \mathrm{MGy}$ or $0.22 \mathrm{MGy}$ HLEBI before rather than after lamination appeared to improve the $a_{\mathrm{s}}$ remarkably from 0 to 40 , and 0 to $42 \mathrm{~kJ} \mathrm{~m}^{-2}$, respectively.

(4) Bending fracture occurred in the CFRP/ABS/CFRP samples for HLEBI dose greater than or equal to $0.22 \mathrm{MGy}$ at mostly all $P_{\mathrm{f}}$. From 0.22 to $0.43 \mathrm{MGy}$-HLEBI doses, the peeling fracture was observed to a lesser extent showing complete bending fracture of one or more constituents (either the core, CFRP or both) becoming dominant.

On the other hand, observed data from HLEBI applied after laminate assembly showed simple bending fracture occurred from the 0.22 to 0.43 MGy-HLEBI doses. Regardless if samples were from the HLEBI applied before or after the laminate assembly, it should be confirmed that the complete bending fractures of ABS core and CFRP sheet with pull-out of carbon fiber from epoxy resin were mostly observed at the impact point in fractured CFRP/ABS/CFRP irradiated with 0.22 and $0.30 \mathrm{MGy}$ at each $P_{\mathrm{f}}$ value. The weakest point of the simple fracture, therefore appears to be the bending fracture of ABS core, as well as CFRP sheets.
(5) Major difference between the new (HLEBI before lamination) and conventional (HLEBI after lamination) methods is gas contamination concentration. The contamination cannot be remarkably detected at the CFRP-ABS interface in the conventional method. When oxygen atoms absorbed the terminated atoms with dangling bonds of ABS and epoxy in the new method, $a_{\mathrm{uc}}$-improvement by small dose of HLEBI from 0.04 to $0.22 \mathrm{MGy}$ can probably be explained by the highly electronegative oxygen atoms as dangling bonds assisting in stronger bonding between the CFRP and ABS surfaces.

(6) The new method of applying HLEBI prior to lamination allowed for more efficient beam contact to the inner core and its surface permitting deeper areas in thick laminated composites such as CFRP/ABS/CFRP to be treated generating dangling bonds, hence strengthening the bulk materials and the CFRP-ABS interface of the thick laminated CFRP/ABS/CFRP constructed with thin or thick surface sheet and thick core can be expected.

(7) Although HLEBI is shown to enhance impact values remarkably in the CFRP/ABS/CFRP sandwich structures, carefulness is recommended in industry quality control to adjust the HLEBI dose to optimum level when treating aircraft parts to maximize safety and strength.

\section{Acknowledgement}

We would like to extend our sincere gratitude to Dr. Keisuke Iwata of Tokai University for his great assistance.

\section{REFERENCES}

1) D. K. Thomas: Plastics Rubber Int. 8 (1983) 53-57.

2) M. B. Dowell: Plastics Eng. 33 (1977) 31-32.

3) T. Yamamoto, S. Nanba, Y. Ebihara and Y. Nishi: J. Jpn. Inst. Metals 74 (2010) 127-130.

4) Y. Nishi, N. Tsuchikura, S. Nanba, T. Yamamoto and M. Faudree: Mater. Trans. 53 (2012) 1288-1294.

5) K. Sonoda, Y. Kaneda, I. K. Nakazaki, Z. Enomoto and K. Murayama: Proc. Symp. on Space Sciences and Technology, (JST No. S0277 A28, 1984).

6) K. Oguri, N. Iwataka, A. Tonegawa, Y. Hirose, K. Takayama and Y. Nishi: J. Mater. Res. 16 (2001) 553-557.

7) K. Oguri, K. Fujita, M. Takahashi, Y. Omori, A. Tonegawa, N. Honda, M. Ochi, K. Takayama and Y. Nishi: J. Mater. Res. 13 (1998) 33683371.

8) K. Oguri, N. Iwataka, H. Izumi, A. Tonegawa, K. Takayama and Y. Nishi: Proc. 2nd Japan-France Seminar on Intelligent Materials and Structures, (University of Louis Pasteur Strasbourg, France) (1998) pp. 142-144.

9) Y. Nishi, A. Mizutani and N. Uchida: J. Thermoplastic Compos. Mater. 17 (2004) 289-302.

10) Y. Nishi, T. Toriyama, K. Oguri, A. Tonegawa and K. Takayama: J. Mater. Res. 16 (2001) 1632-1635.

11) Y. Nishi, M. Mizutani, A. Kimura, T. Toriyama, K. Oguri and A. Tonegawa: J. Mater. Sci. 38 (2003) 89-92.

12) A. Mizutani and Y. Nishi: Mater. Trans. 44 (2003) 1857-1860.

13) Y. Nishi, K. Inoue and M. Salvia: Mater. Trans. 47 (2006) 2846-2851.

14) Y. Nishi, T. Yamamoto, S. Namba, H. Takei and K. Iwata: Mater. Trans. 52 (2011) 73-80.

15) Y. Nishi, M. Uyama, H. Kawazu, H. Takei, K. Iwata, H. Kudoh and K. Mitsubayashi: Mater. Trans. 53 (2012) 1657-1664.

16) K. Iwata and Y. Nishi: Mater. Trans. 49 (2008) 2058-2062.

17) K. Iwata and Y. Nishi: Mater. Trans. 51 (2010) 121-127.

18) ASTM D 6264-98 (1998). 
19) K. Imielińska, L. Guillaumat, R. Wojtyra and M. Castaings: Compos. Part B 39 (2008) 1034-1041.

20) A. S. Vaidya, U. K. Vaidya and N. Uddin: Mater. Sci. Eng. A 472 (2008) 52-58.

21) O. S. David-West, D. H. Nash and W. M. Banks: Compos. Struct. 83 (2008) 247-258

22) L. Aktay, A. F. Johnson and M. Holzapfel: Computat. Mater. Sci. 32 (2005) 252-260.

23) K. Komai, K. Minoshima, K. Tanaka and K. Nakaike: 12th Int. Conf. on Composite Materials, (1999), pp. 1-10.

24) M. Aktaș, R. Karakuzu and Y. Arman: Compos. Struct. 89 (2009) 77-82.

25) H. M. Wen, T. Y. Reddy, S. R. Reid and P. D. Shoden: Key Eng. Mater 141-143 (1998) 501-552.
26) S.-L. Gao and J.-K. Kim: Compos. Part A Appl. Sci. Manuf. 32 (2001) $775-785$.

27) V. Kostopoulos, A. Baltopoulos, P. Karapappas, A. Vavouliotis and A. Paipetis: Compos. Sci. Tech. 70 (2010) 553-563.

28) J. D. Splett, H. K. Iyer, C.-M. Wang and C. N. McCowan: National Institute of Standards and Technology (NIST) Recommended Practice Guide, Computing Uncertainty for Charpy Impact Test, Machine Test Results; Special Publication 960-18, US Department of Commerce: Boulder, Colorado (2008) pp. 27-29.

29) T. Nishida and E. Yasuda: Evaluation of dynamic properties of ceramics (in Japanese), (Nikkan Kogyou Shimbun Sha, Tokyo, 1986) pp. $50-51$

30) W. Weibull: Ingeniörs vetenskaps akademien, nr. 151 (Generalstabens litografiska anstalts förlag, Stockholm, 1939) pp. 12-14. 